\title{
The super-disadvantaged in higher education: barriers to access for refugee background students in England
}

\section{Agata A. Lambrechts ${ }^{1}$}

Published online: 15 February 2020

(C) The Author(s) 2020

\begin{abstract}
In view of the so-called 'refugee crisis' which began in late 2014, there is a growing potential demand for higher education opportunities amongst refugee communities in England and more widely in Europe. Whilst exact numbers are not certain, it is necessary to establish whether such demands can be met at all. Based on in-depth semi-structured interviews with nineteen refugees and asylum seekers residing in England, this study explores refugee background students' perceptions of the barriers to higher education and builds on previous research by including participants of varied ages, locations and study statuses - namely, aspiring to enrol, or currently enrolled in universities. While existing previous research provided extensive accounts of barriers to access, these were presented as separate issues, where in reality, these factors rarely occur in isolation. Thus, the analytical focus in this paper concerns how these different barriers to access not only accumulate, but also inter-relate and exacerbate each other, leading to what can be described as a super-disadvantage. This new term is proposed here as indicating the extreme degree of denial of equal access to educational opportunities experienced by those with refugee background, resulting from the added, independent effect of their migration experiences, status, and the socio-economic realities of living as a refugee. It is argued that this 'super-disadvantage' cannot be overcome without deliberate changes to outreach and support delivered by universities. These must be developed in partnerships with third sector experts and the refugee background students themselves.
\end{abstract}

Keywords Refugee background students $\cdot$ Refugees and asylum seekers $\cdot$ Barriers $\cdot$ Access to higher education · Widening participation

Electronic supplementary material The online version of this article (https://doi.org/10.1007/s10734-02000515-4) contains supplementary material, which is available to authorized users.

Agata A. Lambrechts

Aal513@york.ac.uk

1 Department of Education, University of York, Heslington, York YO10 5DD, UK 


\section{Introduction}

As in other advanced economies, the higher education (HE) sector in England has experienced a rapid expansion of participation in the last century and a half (Meyer and Schofer 2005). Each expansion has been accompanied by calls to increase widening participation for disadvantaged groups, and today the English HE system is at least formally an open one. 'Universal' participation levels of over 50\% have been reached (Universities UK 2017), and there were some remarkable achievements in widening participation, in particular, during the last few decades, including, for example, an increase in women's participation overall. Despite this, many groups continue to be under-represented.

Over the years, to guide policy and practice, an extensive body of literature has been developed, exploring the barriers to accessing and participating in HE, as experienced by different groups. The focus in England (as elsewhere) has been in particular on adults from lower-income groups, people with disabilities and groups with minority status. More recently, studies have been exploring the perspectives of mature entrants and those leaving care, reflecting shifting national priorities and the changing profile of the student population, and investigating previously unknown challenges faced by those who may perhaps benefit most from HE opportunities. To date, despite the continuously growing levels of human displacement globally, and in view of the current UNHCR estimate that only about $3 \%$ of the world's 25.9 million refugees have access to HE opportunities in the host states - a long way from the target of $15 \%$ set for 2030 (UNHCR 2019) ${ }^{1}$ — the development and implementation of a suitable policy frameworks for access to HE for those with refugee backgrounds in Europe in particular, has been somewhat variable, and mostly inadequate. ${ }^{2}$ The related field of educational research, both in England and elsewhere, remains relatively under-developed.

This is partially due to the difficulties in ascertaining the actual number of those with refugee backgrounds in universities (Stevenson and Baker 2018), and the ethical and methodological challenges of researching with hard to reach, marginalised communities (e.g. Bailey and Williams 2018). Lack of national policy frameworks to support refugee education and increasing anti-immigrant sentiments in Europe and across the world further explain why the experiences of refugees in host state universities are both under-researched and undertheorised. Additionally, as noted by Stevenson and Willott (2007), support needs of refugee students may be perceived to be similar to those of other disadvantaged groups - indeed, a view held by more than half of England's universities which do not currently consider refugees as a group with distinct needs (Lambrechts 2020b).

This article examines the barriers to HE access for adults with refugee backgrounds as experienced and perceived by themselves - as opposed to perceptions and assumptions about these barriers that may be made by those working in universities - to ascertain whether they are indeed just facing the 'usual' obstacles or something else entirely. It is argued that while some of the barriers to access are shared with other disadvantaged groups, the difficulties may

\footnotetext{
${ }^{1}$ For humanitarian rationale and the potential economic benefits, see Lenette 2016. There are also substantial legal basis for supporting RBS access to universities - access to HE is a human right, as enshrined in the Universal Declaration of Human Rights (Article 26) and many other international and regional legal instruments. It is one of the global indicators for achievement of UN Sustainable Development Goal 4, and promoting access for refugees, specifically, is one of the objectives of the New York Declaration for Refugees and Migrants (United Nations 2016), further reiterated in the subsequently developed Global Compact on Refugees, as affirmed in December 2018.

${ }^{2}$ For an overview of policies, measures and monitoring practices in Europe, see Eurydice (2019).
} 
be especially pronounced because of the unique conditions of refugees, with further barriers being specific to refugee background students' (RBS) circumstances. ${ }^{3}$

The analytical focus (and the key scholarly contribution) concerns how these different barriers to access not only accumulate but also inter-relate and exacerbate each other, leading to a super-disadvantage. This new term is proposed here as indicating the extreme degree of denial of equal access to educational opportunities within the existing structures of host states, experienced by those with refugee backgrounds and resulting from the added independent effect of their migration experiences, status and the socio-economic realities of living as a refugee. It must be noted that the term is not meant to set up a hierarchy of disadvantage - to indicate a disadvantage greater in relative terms to that experienced by other individuals or groups - but to foreground the complexity, gravity and compound nature of the problems faced by RBS to policymakers, practitioners and researchers. This is so that appropriate research frameworks, and, more importantly, appropriate policies and practices can be developed to help tackle these interlinked issues. Although the current study is based on data collected in England, drawing, and building on existing local research in particular, findings are presented as a specific case of a more general issue, and the analytical consequences are considered to be of wider relevance, beyond the English national context.

\section{England's HE responses to the 'refugee crisis'}

In England, both domestic ('home') and international students have to pay tuition fees for all levels of university study. Admissions are competitive, but the cap on enrolment numbers was removed in 2015/2016 and universities can recruit as many students as they can teach. Refugees are eligible to undertake and receive HE under the rules applicable to citizens. This means paying fees at the lower 'home' level, as well as immediate access to the publicly funded student loans, with exemption from the set period residency requirement rule which applies to other applicants. There is nothing in the immigration rules which would prevent asylum seekers, or those with tolerated stay permits, from undertaking a course of study at a university (except those whose claims have been rejected and who have been released on immigration bail, pending removal). Yet, while the exact number of applicants and students with refugee backgrounds is impossible to ascertain currently, findings from a wider research project forming the basis for this paper suggest that they are under-represented in our universities. Only a few thousand are currently undertaking study across all levels, including a small number of asylum seekers (who are often beneficiaries of scholarship programs available in some universities). ${ }^{4}$ This can be at least partly attributed to RBS invisibility from the relevant policies - access to $\mathrm{HE}$ is missing from England's migrant integration policies, while 'refugees' as a group is not considered in any of the national HE policies (Eurydice 2019).

\footnotetext{
${ }^{3}$ This term is used throughout this article to describe collectively those seeking sanctuary in England, both current and potential HE learners. Terms 'asylum seekers' and 'refugees' are used separately where research findings relate to only one of these groups. 'Refugees' (R) in those places means those who have had a positive decision on their claim for asylum, while 'asylum seekers' (AS) means those who have formally applied for asylum and are awaiting a decision on their application.

${ }^{4}$ In the absence of duty to report such numbers in England - data is largely missing or patchy. The estimated number of RBS entrants in 77 universities which collect at least some relevant data (based on rounded numbers provided), in the 5-year period between 2013/2014 and 2017/2018 academic years, was 3156 (Lambrechts 2020).
} 
This was addressed for the first time (at national level) in response to the so-called 'European refugee crisis' in 2016, when the Office for Students, the independent regulator of English HE, added 'refugees' as a widening participation target group, offering legitimacy to universities with aspirations to make a difference in this area. Universities can now choose to focus some outreach activities and earmark part of their budgets for equal access provision to support this group. Indeed, a closer examination of access agreements, which describe the institutional ambitions for change, and the targets set for the financial investment necessary to deliver the said changes, revealed that a third of England's universities now include some provisions in those statements. Many more universities - even if they do not mention it in their access agreements - make a positive effort to make 'refugees welcome' in the communities and on campuses in England, in particular by creating scholarships or reducing fees (Lambrechts 2020a). Nevertheless, a third of England's universities do not collect any data related to applicants or students with a refugee background, most others only collecting some, being thus unable to gauge how well-or badly - they do in attracting applicants with a refugee background. Most do not have targeted interventions to support access of RBS beyond individual scholarships, and only a handful offer full maintenance support. The existing institutional practices - while unquestionably a good start - seem often to be driven by interested/dedicated individuals and have sometimes been set up hurriedly (Lambrechts 2020b). Although there has been a lot of positive movement in the sector, with universities coming together to share best practice, it is rarely questioned on what basis are strategies determined to be 'best'. It can be argued that without appropriate practices of evaluation and considering the current absence of consistent data reporting on RBS in HE, the evidence cited is anecdotal, and thus, such claims cannot be unequivocally accepted.

\section{Previous research}

Although evidence-based policy and practice in widening participation are critically important to England's universities and form part of the criteria for access agreements spending (Department for Business, Innovation and Skills 2014), the research evidence about RBS participation remains scarce. Results from the handful of available studies with refugee communities (Alberts and Atherton 2017; Elwyn et al. 2012; Morrice 2009; Morrice and Sandri 2018; Stevenson and Baker 2018; Stevenson and Willott 2007) indicate that there is no shortage of aspirations to access HE amongst refugees in England, but they face barriers to university admission, including financial costs, a lack of relevant expertise in schools and colleges and resulting lack of appropriate information and guidance. Interruptions in education either in the country of origin, or once arrived in the UK, mean that RBS do not always achieve the grades required for progressing onto HE, and lower-level language ability were also discussed. ${ }^{5}$ While these earlier reports offer a much-needed contribution to the field, we do not yet have a full picture. Although these studies provide an extensive account of the barriers identified, these are presented as separate issues, where in reality, these factors rarely occur in isolation. Without considering how the barriers relate and aggregate, there can be no

\footnotetext{
5 These are broadly comparable with barriers experienced by refugee youth trying to access post-16 education in England as reported by Doyle and O'Toole (2013); there are similarities with other European contexts (see for example Schneider 2018, for an overview of barriers in Germany) and further afield (with a comparatively large body of research on Australian context, including, for example, a recent report by Hartley et al. 2018).
} 
real understanding of RBS' marginalisation. Consequently, the current paper - while building and drawing on the findings from the previous research-differs from these past studies in several respects, as outlined below.

\section{Theoretical base}

This paper draws on the existing framework of 'barriers', with the range of difficulties faced by adults who wish to access post-secondary education classified into four main groups in the literature: dispositional, academic, situational and institutional (Cross 1981; Potter and Alderman 1992). In terms of research, the concept of barriers not only aids our understanding of the uneven patterns of HE participation but practically guides policymaking, as 'it contains its own solution - the removal of the barriers', which should, at least in theory, ensure equitable access and participation (Gorard et al. 2007, p.5).

Although the concept of barriers is used widely in the recently emerging literature on $\mathrm{HE}$ opportunities for RBS, most authors do not group the different factors under the headings as developed by Cross (1981). This classification, however, seems very useful indeed as some of the barriers are clearly more amenable to change by the efforts of universities than others. Categorising the issues makes it easier for universities to develop a hierarchy of effort to be involved in the elimination of the different issues, with institutional barriers seemingly the easiest for them to do something about. Nevertheless, as is the main argument in this paper, universities are also capable of, and have a certain level of responsibility, to develop measures which will counter the difficulties categorised as other than institutional — in so far at least, as they exacerbate the barriers which are classed as such. Notably, the discussion in this article is confined to the links between the institutional and situational barriers (as defined in the findings section below). This is not to imply that links with other barriers are less critical or extensive, but, firstly, to shift the focus away from individual 'deficits' to more structural and systemic barriers, and secondly — more pragmatically — to avoid an oversimplified formulation of all, and to keep the discussion focused.

\section{Method}

\section{Aims}

This paper explores refugees' perceptions of the barriers to higher education and builds on previous research by including participants of varied ages, locations and study statusesnamely, aspiring to enrol, or currently enrolled in HE. The voices of those who have not yet enrolled in HE are especially neglected in the existing literature. The analysis focuses on how distinct barriers relate to and exacerbate one other, and what this might mean for universities tasked with narrowing social and economic inequalities through ensuring equal educational opportunities.

\section{Data}

Data was collected through in-depth interviews, using a standard interview protocol including open-ended questions with prompts (Supplementary material). The interview schedule was 
designed based on a review of the literature and professional experience of the researcher (who previously worked as student welfare and immigration adviser at an English university). It was piloted with one current (refugee) student to test the questions and ascertain whether the subject can be adequately captured by the proposed schedule. Additional questions and prompts were added after the pilot interview.

In total, 14 face-to-face and 5 email interviews were conducted between November 2017 and April 2018. Email interviews included multiple (up to five) exchanges with the participants, following the same interview protocol as in face-to-face interviews. These were offered as an option to those who were unable - or not willing - to meet with the interviewer in-person.

\section{Sampling}

The purpose of the sampling was not to gain statistical representation but capture a wide range of perspectives from a cross-section of refugee background population. Thus, a maximum variation purposive sampling was employed: participants with communicative level of English (to circumvent the need for interpreters), currently studying at degree level or self-identifying as wanting to go to university, of various age, migration status, gender or origin were identified and recruited via a network of contacts with third sector organisations and university personnel. The final sample included nineteen participants aged between twenty and fifty, originating from thirteen countries. Participants had various educational backgrounds - some primary level qualifications, others completed university degrees - and represented various socio-economic groups before migration. Six were current students, four held offers from universities, one made an application, and eight were not applying for a university place at the time of interviews (Table 1). The size of the sample was dictated by pragmatic reasons - time and financial resources available for this study, as well as difficulties in reaching the target population.

\section{Ethics}

The ethical integrity of this project was paramount: flexibility in organising the location and conduct of interviews was offered as much as practically possible. Before starting their

Table 1 Demographic characteristics of interview participants

\begin{tabular}{|c|c|c|c|c|c|}
\hline Respondent & Number & Gender & Migration status & $\begin{array}{l}\text { Length of } \\
\text { displacement }\end{array}$ & $\begin{array}{l}\text { University } \\
\text { type }\end{array}$ \\
\hline Current students & 6 & $\begin{array}{r}3 \text { male, } 3 \\
\text { female }\end{array}$ & $\begin{array}{l}1 \text { refugee, } 4 \text { asylum } \\
\text { seekers, } 1 \\
\text { humanitarian } \\
\text { protection }\end{array}$ & $2-7$ years & $\begin{array}{l}4 \text { elite } \\
\text { research, } \\
2 \text { modern }\end{array}$ \\
\hline Offer-holders/applicants & 5 & $\begin{array}{r}3 \text { male, } 2 \\
\text { female }\end{array}$ & $\begin{array}{l}3 \text { refugees, } 2 \text { asylum } \\
\text { seekers }\end{array}$ & 18 months -5 years & $\begin{array}{l}1 \text { elite } \\
\text { research, } \\
1 \text { modern, } \\
3 \\
\text { red brick }\end{array}$ \\
\hline $\begin{array}{l}\text { Non-applicants } \\
\text { (self-identified } \\
\text { as wanting to go } \\
\text { to university) }\end{array}$ & 8 & $\begin{array}{r}5 \text { male, } 3 \\
\text { female }\end{array}$ & $\begin{array}{l}6 \text { refugees, } 2 \text { asylum } \\
\text { seekers }\end{array}$ & $1-15$ years & \\
\hline Total & 19 & & & & \\
\hline
\end{tabular}


interview, participants were informed of the purpose of the study, their informed consent was obtained in writing, and it was made clear that they could refuse to answer any questions asked. At the end of the interview, participants were offered a chance to review their answers, withdraw any statements made or withdraw from the study entirely. The interviews were anonymised at the point of data collection and kept separately from consent forms to protect participants' identities.

\section{Analysis}

Interviews were transcribed verbatim and coded in NVivo, following the framework approach to thematic analysis (Clarke and Braun 2013). Following familiarisation with the transcripts, to gain a general sense of the meaning of the interview content, key issues and themes were identified, which guided the coding process. Upon deciding on the use of the 'barriers' classification framework, the themes were reviewed and defined using visualisation tools for codes. Charts and concept maps were used to look for deeper meanings and explore the connections between different groups, and to organise the information into a final succinct matrix of themes, grouping the identified barriers to access into the four different categoriestwo of which are reported on in this paper.

\section{Key findings}

\section{Institutional barriers}

In explaining the difficulties in accessing HE programmes, issues that can be classified as institutional were cited the most. ${ }^{6}$ Sixteen participants have focused their accounts on these, with over $40 \%$ of references coded under this theme. Some of these difficulties result from national policies imposed on universities, others are a consequence of structures and processes put in by universities themselves - overlooking the legal, economic and social realities of RBS (the situational barriers), and ignorant of the exclusionary constraints these inflexible systems and processes result in. Within this top-level category, three sub-categories have been identified and labelled as: informational, procedural and financial factors.

\section{Informational factors}

A central finding emerging from participants' accounts was the lack of timely, accessible, quality information available to them. Usually new to the country (see also Newcomer Factors below), RBS rely on the government, third sector organisations and other official bodies to provide them with all the information - and have no control over what these state and nonstate bodies decide is the information they need. This lack of information permeates every stage of their experience, as has been evidenced in few studies already, both in the UK and other national contexts (Elwyn et al. 2012; Shakya et al. 2010; and Stevenson and Baker 2018). Firstly, RBS are unaware of their legal rights in relation to HE participation - these are not communicated with them as part of the immigration process, or in the information packs

\footnotetext{
${ }^{6}$ According to Cross (1981), institutional barriers relate to the limitations inherent in the way institutions design, deliver and administer learning activities, biased or ignorant of the needs of the disadvantaged groups.
} 
they receive in National Asylum Support Service (NASS) ${ }^{7}$ accommodation or council provided housing for refugees arriving under the resettlement programme. ${ }^{8}$ RBS are also unfamiliar with our education system and processes (see Procedural Factors section below) and do not know their financial entitlements (see: Financial Factors). The participants suggested that third sector organisations working with forced migrants focus their efforts on the provision of basic needs - legal advice, help with benefits and housing, etc. - as they lack the capacity and/ or expertise to offer information and advice on HE. Indeed, as reported by several participants, charity workers (as well as college and university staff, and family members) often misinform them-telling the asylum seekers in particular that they cannot attend a university or access funding, as described by Zachary (34, AS, current student):

(...) I went online and asked some of the people at the Red Cross who we've worked with us as asylum seekers (...) 'have you heard?' And none of them heard. Everybody kept saying, no you are not allowed to [study], we don't know...

Participants reported the information about requirements for holders of foreign qualifications on university websites to be inconsistent, found most institutions neglect to provide information aimed at RBS specifically, and lamented the fact that many universities fail to effectively communicate even about the specific opportunities created for the RBS. Those who have applied for the funded places have often found out about them by chance and last minute, subsequently failing to complete the application forms and gather necessary documentation in time. A regrettable consequence of this has been some institutions struggle to fill places offered on a funded basis (see Murray 2019). Lack of communication between universities, colleges, and third sector, to disseminate information about these opportunities was repeatedly criticised by the participants, who believe it to be relatively easy for universities to outreach to RBS:

Asylum seekers are the easiest people to track down (...) Just [be] specific - there is a group that meets at Newcastle, there is a group that meets at Middlesbrough, there is a group...wherever. (...) Go and say 'hi, we're from [X university] and we have this fantastic opportunity, here is our paperwork, if you are interested just look it up'. That's it.

\section{(Zachary)}

Before moving on to discuss procedural factors, and how they link with the abovementioned ones, it should be stressed here that those who secure a place at a university and obtain financial resources to support their studies, oftentimes face lack of appropriate, tailored prearrival information and guidance. Several participants in this study have raised the issue of universities not talking to them about the effects of moving to a different city to study may have on their accommodation and benefit entitlements, about the details of their scholarship, opening a bank account (required for their scholarship payments but difficult to open with limited documentation), or the academic expectations they should prepare themselves for. The impacts of this lack of information have been profound on RBS experiences both during the period of transitioning into university, and later in their HE journeys.

\footnotetext{
${ }^{7}$ NASS is a section of the UK Visas and Immigration division of the Home Office, responsible for accommodating asylum seekers.

${ }^{8}$ These packs generally include local information, e.g. where to register with the doctor or how to enrol children in a local school.
} 


\section{Procedural factors}

The next group of key inhibiting factors was the admissions and enrolment procedures. The level and type of credentials required for admission constitute a challenge, with most participants finding the procedures to be inflexible and bureaucratic. To begin with - and linking directly to, or indeed overlapping with the informational barriers (as discussed above) (Fig. 1) - it is not always easy for the applicant to find out whether an institution will accept their qualifications, as explained by Freya (23, AS, current student):

I basically contacted forty universities who did the scholarships - but I wanted to find out if they would accept me with my qualifications. (...) And then I found out how so many different universities have different ways of contacting - some of them didn't even reply, some replied straight away, some of them took a while.

While some RBS have the acceptable prior qualifications, they may not be unable to produce documentation to confirm this, left behind, or lost during their migration journey, as recounted by several participants, including Harry (26, R, Offer Holder):

I threw my bags to save three people. All my qualifications were in my bag. At the time it was a big decision for me - I protect my future or save three children's lives. Of course, life [is more] important. Piece of paper is a piece of paper... I survived... but that's why I was struggling (...).

Although it is sometimes possible to get copies of certificates, the cost and formalities involved make it impossible for most. Restrictions around work and minimum statutory support - as discussed below in the Financial Factors section, mean that asylum seekers and newly granted refugees in particular cannot meet these costs. Generally, no alternative in-house forms of skills/knowledge assessment are offered by universities, and candidates (like Harry) are forced to retake lower level examinations/qualifications.

Another commonly emphasised factor was the formal language requirement. Participants have generally agreed that language competence is necessary for effective participation in HE learning and as such a valid part of the admissions process, but most struggle to obtain the required certification. This is partially due to the inadequate language training provision offered for those seeking sanctuary in England (as discussed in the Situational Barriers section below), but for those who have the skills necessary, the barriers may be more prosaic. Universities typically require that applicants obtain an IELTS (or alternative international standardised test of English language proficiency for non-native speakers) certificates - all of which involve a costly examination, ${ }^{9}$ which can only be completed in a designated testing centre, usually located in larger cities around the country, thus, often necessitating (costly) travelhere too, clear link can be seen with the Financial Factors as discussed below. Again, generally, no alternative in-house examinations are offered by universities.

The final procedural factor is the mode of application itself. In England, all undergraduate (and some postgraduate) applications are made through the Universities and Colleges Admissions Service (UCAS). Applications are made online, but where

\footnotetext{
${ }^{9}$ Test fees in England in 2018 varied between $£ 140$ and $£ 200$.
} 
other applicants often receive help navigating the website from their school or college, RBS are left to work it out alone:

It wasn't that straightforward to do it yourself. Because - I think because of confidence.

It wasn't about the language or understanding the context of what is written down. It was kind of about the technique, how to use the website. There was a video on how to do it (...). But it seemed a bit complicated for me.

(Harry)

Universities and UCAS do not offer tailored guidance on how to complete an application and personal statement based on the RBS' often unusual educational background, without access to documentation and without experiences similar to those of domestic applicants (again, other applicants often receive personalised help in drafting of these statements, either from their educational provider or an agent). Further, applicants are required to submit a written reference provided by someone who knows them academically and can talk about their suitability for HE. UCAS advises applicants to ask their tutor, teacher, principal or headteacher from current or recent school or college, or an employer or volunteering supervisor. For RBS who have not participated in any courses, and who have been in England for a relatively short amount of time and moved around the country at the Home Office's order, it can prove difficult to find a suitable referee. Finally, there is an application fee to pay-between $£ 18$ and $£ 24-a$ small amount for most applicants, but for RBS often living in destitution, making the payment for an application means they must make cutbacks elsewhere as explained by Freya:

You basically have to not eat for certain amount of days to pay that.

The above is perhaps the most fitting example of how the university admission processes - applying equal conditions to all potential learners-can lead to de facto inequality, when designed and administered in ignorance of the unequal socioeconomic conditions of those with refugee backgrounds - associated with the migration journey itself and the process of seeking asylum in England. Those broader economic considerations are discussed further below, in the situational barriers section, but for now, the financial issues related directly to study costs as well as statutory and institutional funding options are discussed.

Fig. 1 Ways in which the procedural factors intersect with others as highlighted in this section

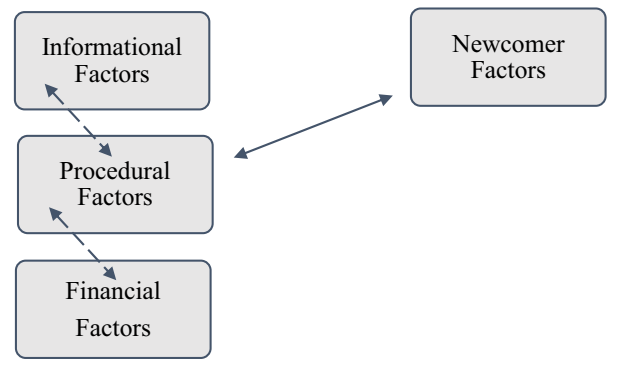




\section{Financial factors}

Participants in this and other recent studies in England (e.g., Morrice and Sandri 2018) confirm that financial concerns hinder HE access for many RBS. Firstly, the already mentioned (see Informational Factors section above) significant gap in understanding of the financial support entitlements for applicants with different immigration statuses - student loans system in England is complex, and participants have noted that easily accessible, clear information about eligibility or residency requirements online is scarce. Further, staff and volunteers working in colleges and third sector organisations were mostly unable to advise them appropriately.

Notably, unlike those with recognised refugee status, ${ }^{10}$ asylum seekers are not eligible to access statutory funding. Moreover, they face unfavourable fee assessment - universities generally consider them to be 'international students' and require them to pay a higher level of tuition fees. This again is not communicated, as described by Thomas (24, AS, Current Student):

I was accepted to study (...), unfortunately, the university considered me as an overseas student which meant I had to pay $£ 13,000$ (...). I did not know that I was going to be charged $£ 13,000$ in the beginning. I raised $£ 3,500$ on GoFundMe and got a charity contribution to make $£ 6,500$ (...) but this was just enough to get enrolled...

This unfavourable fee status assessment has been recently extended to those with humanitarian protection (HP). ${ }^{11}$ In the past, those with HP status applying for a course in England had to have been a resident in the UK for 3 years before the start of their course to access student loans, but they could access university and be automatically considered as 'home' student for fee purposes. From 1 August 2019, following changes in the fee regulations by the Department for Education (England), new students have to meet the 3-year residence criteria first or face international student fees, placing yet another barrier to access for those who may be otherwise able to begin their course (using own or bestowed funds). ${ }^{12}$ This is likely to increase the competition for the already limited scholarships (discussed below), which for many-not wanting to wait for another 3 years to continue their education - will become the only route into HE.

Although 48 universities in England (in 2018/2019) offered fee-waivers to a small number of RBS, and some offered partial (18), or even 'full' maintenance support (18), this could only be accessed by those who have met all the entry requirements and were able to join the programme. Costs associated with the application and meeting of formal requirements (namely the language certification and replacing and/or translating documentation from home country, as noted above in the Procedural Factors section), as well as cost of moving out of publicly funded accommodation and into university halls or privately rented housing, are prohibitive for many and limit the range of institutions RBS can apply to (Fig. 2).

Now, while scholarships offered by an ever-growing number of institutions (particularly since 2015) undeniably facilitate pathways into HE for a number of RBS, there are several issues which participants felt universities need to reflect on when considering the introduction

\footnotetext{
${ }^{10}$ Any time in previous degree level study, however, in the home country or a third country, is taken off the tuition fee loan entitlement.

${ }^{11}$ Humanitarian protection is a form of protection granted to asylum seekers who are not eligible for refugee status but cannot be returned to country of return because of objective and serious personal situations.

12 Thanks to campaigning by the Student Action for Refugees - a national network of student groups working to improve the lives of refugees in the UK - a number of universities now classify those seeking asylum as home students, and as such charging them lower fees. Presumably, STAR will also campaign for universities to lower the fees for students with HP status.
} 
of a scholarship programme, or when evaluating an existing one. Firstly, the level of funding made available needs to be carefully considered. In 2018/2019, only five institutions offered maintenance support equivalent or higher to the maximum maintenance loan amount available in England - which has been reported to leave home students struggling financially, having to subsidise the loan with work and/or rely on a regular contributions from their parents (e.g., Antonucci 2016) — neither of which are possible for majority of RBS. Secondly, participants reported that each university has its own procedures, with separate forms and supporting documentation needed, with information about the selection criteria often "unclear and not transparent" (see also Informational Factors above):

This lack of information from the universities' side was quite daunting especially knowing how competitive the opportunity is. Most universities had scholarships for about 2-3 students each academic year and it wasn't very obvious what they were looking for aside from grades and personal statement.

(Ella, 20, Humanitarian Protection, Current Student)

Further, several institutions, perhaps unwittingly, put procedural roadblocks in the way of RBS, by requiring applicants to make decisions which ultimately limit their chances to access HE, as explained by Freya:

[W] hen you had to apply for the bursaries, the main condition was that you should have that university as your firm choice. So, [university 1] wanted me to have [university 1] as a firm choice, [university 2] wanted the same and [university 3] wanted the same. So, I basically had to weigh my chances out and go for a firm choice and apply for the scholarship to the one I was thinking I would [get].

Ultimately, the number of scholarships available is still limited and these can lift only a handful of individuals at a time into the system. While access to statutory funding remains restricted,

Fig. 2 Ways in which the financial factors intersect with others as highlighted in this section

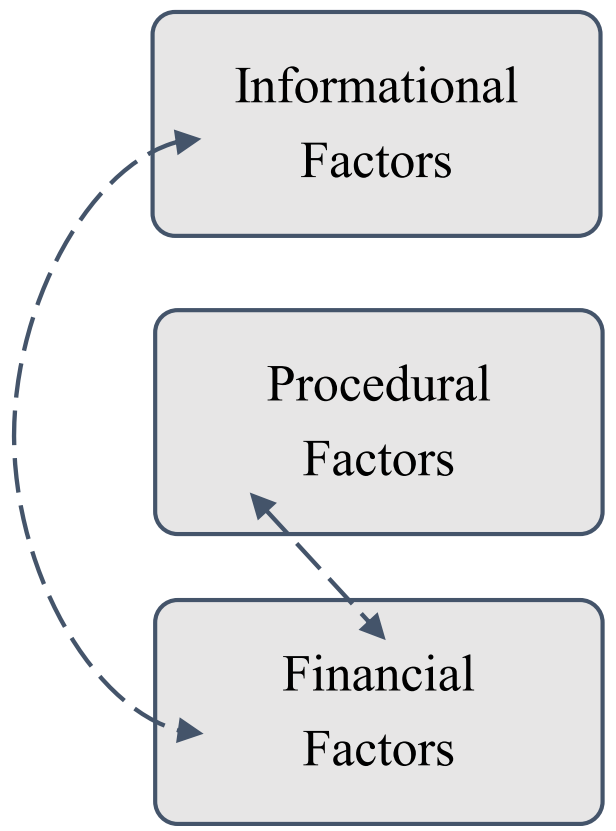


additionally paired with several situational barriers - as discussed below - thousands of people will endure exclusion from England's educational system, their potential and contribution untapped.

\section{Situational barriers}

All of the previously mentioned institutional barriers are linked to, overlap with or are exacerbated by the situational ones, which can be defined as barriers relating to the individual's broad circumstantial conditions (Cross 1981). As noted by Dench and Regan (2000), placing the responsibility to overcome such difficulties on the individuals, and framing these as 'deficits' on their part is highly problematic, as it dismisses the impact of structural issues. It is a view also presented in this paper, where it is argued that universities cannot effectively support access for RBS without understanding their socio-economic conditions and life within uncertain legal realities. Also, how such barriers interplay with the institutional ones, or how they may be perpetuated by the lack of support and inflexibility from universities.

\section{Newcomer factors}

As noted above, the major institutional barrier was the lack of timely, accessible information about RBS rights and entitlements to HE and related issues (see: Informational Factors). Although lack of information is a factor common with other under-represented groups (see for example Sanderson 2001, for a discussion about informational barriers faced by students with disabilities), it can be argued that those with refugee backgrounds are more vulnerable to this. This is because they are, in most cases, new to the country and therefore lack both the understanding of the rules and resources necessary to exert active agency, and do not have a network of relevant, supportive social relationships. Participants reported that they generally lack opportunities to integrate with citizens - people living, studying and working here, and are familiar with the system, who could provide guidance and support their higher education aspirations.

The effect of RBS recent arrival in the country can be further related to the procedural factors (Fig. 3) - namely the type of credentials and level of language fluency required. Some participants reported that despite previous experiences of education (in some cases including HE) in their home country or elsewhere, their knowledge and competencies were considered insufficient/ irrelevant in the UK HE context. Unlike other newcomers who migrate to England for economic or familial reasons, or to study at a university as an international student - who are generally able to prepare for their migration by researching the educational system and institutions, learning the language and obtaining relevant language and academic qualifications, and preparing financiallythose leaving their countries for humanitarian reasons, are unable to make such preparations.

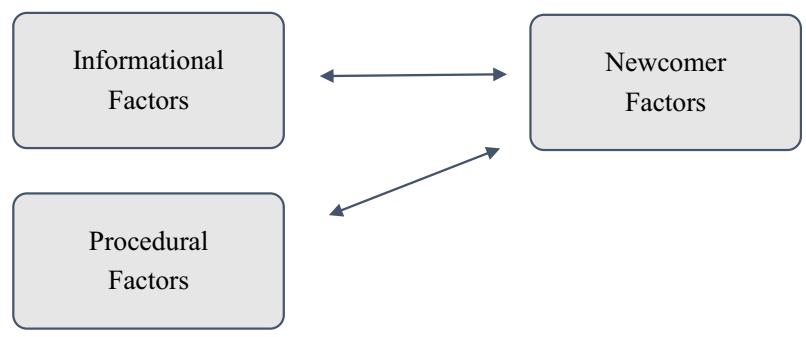

Fig. 3 Ways in which the newcomer factors intersect with others as highlighted in this section 


\section{Environmental factors}

While poverty is not uncommon in modern-day England (e.g., OHCHR 2018), the prevalent 'hostile environment' policies in England ${ }^{13}$ have weakened the benefit entitlements and restricted other forms of support available to asylum seekers and refugees. They have also been linked in recent reports with the increase in destitution amongst those groups, exceeding the levels of relative poverty faced by those from other marginalised groups (e.g., Joseph Rowntree Foundation 2018). Poverty and the linked difficulties in covering the costs of the application to a university (in the absence of alternative modes of application, one of Procedural Factors discussed), and moving to a new location or commuting, purchasing necessary books and equipment etc., are also experienced by many UK nationals. However, the additional cost faced by RBS, as discussed above (see: Financial Factors), and their particular circumstances, mean that these issues are particularly pronounced. Many participants reported the difficulties of fulfilling their most basic of needs during the period of waiting for their asylum application decision when they were reliant on the support of NASS. This provides them with accommodation and a weekly personal allowance, equating to about $£ 5.39$ per day-equivalent to only about $51 \%$ of the current income support received by single non-asylum seekers (aged over 25) in England.

The poverty which dampens prospects for HE is further entrenched by restrictions on employment. Participants described their frustrations with the current rules, under which asylum seekers in England are not permitted to work whilst awaiting a decision on their application, except with special permission, and if the job is included on the list of occupations with a shortage of workers (Home Office 2016). This includes roles in engineering, teaching, science, healthcare and IT-most requiring HE qualifications which they cannot obtain without access to statutory funding and/or support from the universities. Although those granted refugee status have a prima facie permission to work, refugees' unemployment rates in England have been historically well above the national average. ${ }^{14}$ Although no current data is available, there seems to be a consensus amongst third sector representatives and the RBS participants in this study, that employment opportunities for refugees remain very limited.

The highest cost for any student in England attending a university too far to commute from home is that of accommodation. Refugees who have the same rights as citizens, and as such may live in social housing before starting the course, would become ineligible upon commencement of a full-time course. Asylum seekers experience an additional layer of difficulty: NASS accommodation in England is offered under an overriding principle of allocation on a 'no-choice basis', mostly in areas of lower housing demand and low housing costs. Although asylum seekers can request transfers to accommodation in a different location, according to Home Office guidance, such requests are only likely to be considered in exceptional circumstances and requests due to moving to university would normally be refused (Home Office 2017). Therefore, the asylum-seeking student would have to give up their publicly funded accommodation and move to private sector housing. Unfortunately, under current regulations (Immigration Act 2014 which was amended by the Immigration Act 2016, and the Immigration (Residential Accommodation) (Prescribed Requirements and Codes of Practice) Order

\footnotetext{
${ }^{13}$ A set of administrative and legislative measures designed to make the country an unattractive migration destination for those who have not yet travelled, and a place with difficult living conditions for those who have already arrived - in the hope that they may voluntarily leave (LIBERTY 2019).

${ }^{14}$ See: RISE (2013); the UK data was issued by the Home Office in 2010.
} 
Fig. 4 Ways in which the environmental factors intersect with others as highlighted in this section

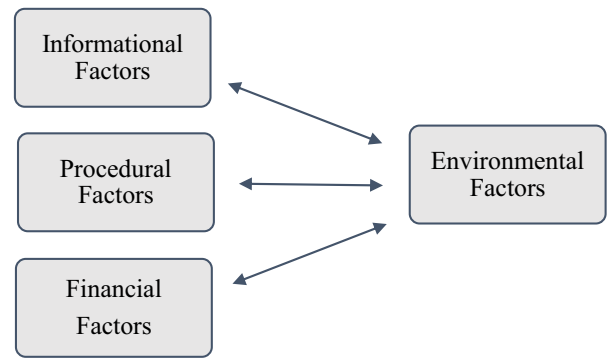

2014), asylum seekers in England do not have an automatic 'right to rent', as explained by Ella:

As an asylum-seeking student, I could not rent or live in private student accommodation outside campus. All agencies and landlords are legally required to ask for passport/visa information from students to ensure they are legally eligible to rent. I was not eligible and therefore had no choice but to live on campus (...).

Asylum seekers like Ella can rent a property if landlords obtain permission by contacting the Landlord Checking Service, but because of this burden, the scheme places on the landlords, finding one who is willing to take them on as tenants can prove difficult. In any case, as is clear from the above statement, this is not something that RBS are necessarily aware of, nor something that universities provide information about (see also: Informational Factors). These difficulties lead to RBS' reliance on (generally) more expensive university accommodation, resulting in them potentially becoming destitute, despite any scholarship they may receive (unless it includes free accommodation!) Once more, a strong link to the financial factors can be seen here. (Fig. 4).

\section{Educational factors}

Many participants who have discussed difficulties in meeting the language conditions of university offer described the level of language proficiency required as problematic - most universities require minimum IELTS scores between 5.5 and 7.0 (or equivalent scores for the other examinations accepted). ${ }^{15}$ Although adult asylum seekers and (unemployed) refugees can attend funded English for Speakers of Other Languages (ESOL) courses in England, the access is often delayed, with asylum seekers only becoming eligible 6 months after submitting the immigration application, and places not always readily available. This causes frustration for RBS stuck in a limbo - unable to work, study or even learn the language:

I went to [college] and they told me just to wait [for] six months. That was the first time. And the second time when I went to them (...) they said [to wait] 20 days and after that you come for assessment and we will know what level are you. And after that we will tell you when your studies will start. And they said that probably it will start in September. And this is a long time to spend, like one year, without any studies in the country.

(James, 26, AS, Non-applicant)

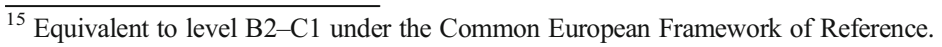


While the funded ESOL courses could, in theory, take RBS to the required level of efficiency, the provision seems to be concentrated on the lower, entry- level qualifications, as described by Freya:

They are only concerned about (...) the minimum [language skills], like going to the shops or meeting a GP, these kinds of thing.

Participants reported only very limited training available to develop higher level language skills necessary to pass the accepted examinations. This gap is sometimes filled by third sector organisations, where funding allows, with several participants reporting to have attended IELTS preparation courses either run by community organisations or privately run courses funded (on a case-by-case basis) by those organisations. The extent of support indicates that there is a demand for high-level language courses, and points to failures in state provision in this area, despite its claims to the contrary.

Next to language requirements, the level and type of credentials required for admissions were discussed above as key procedural factors. As mentioned, the inability to present documentation can be linked to the hasty departures from a home country, and the often-precarious ways in which RBS travel to England. However, it can be also linked to gaps in educational histories, which were reported by almost all the participants in this study (Fig. 5). This had a particular impact on the slightly older participants, who often described disappointment in having to re-do lower level qualifications to progress to $\mathrm{HE}$ in England:

[W]hen I asked what the qualification that I'll need they [the university] have told me that even though I've done GCSE and I've done university, I still have to get GCSEs because it's like I'm starting over. It's been years, and I still have to do my GCSE again (Elizabeth, 50, R, Non-applicant)

Refugees can access training with concessionary rates if they are unemployed and in receipt of income-based benefits (or if they are employed but aged 19-23, studying for first full level 2 or 3 qualifications, or aged 24 and over and studying for GCSE Maths or English). Although colleges should also offer concessionary rates (or fee remissions) for asylum seekers under NASS, there is again the delay of 6 months before they can access this, and participants reported that colleges are not always clear about their eligibility for concessions. It should be noted that the concessionary rates can be too high considering the low-income support available to RBS.

Fig. 5 Ways in which the educational factors intersect with others as highlighted in this section

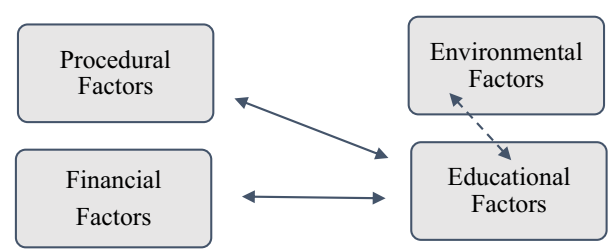




\section{Conclusions: the super-disadvantage}

In view of the 'refugee crisis' which began in late 2014, there is a growing potential demand for HE opportunities amongst refugee communities in England and more widely in Europe (where some 1.5 million refugees and migrants have arrived since late 2014, with around 50\% of new asylum applicants aged between 18 and 34 (Eurydice 2019)). Whilst exact numbers are not certain, it is necessary to establish whether such demands can be met at all. Unlike other European states (namely Germany), in England - in-line with the abovementioned 'hostile environment' policies - there is a lack of system-level planning by policymakers. Although refugees (including those awaiting an immigration decision) are relatively safe, they live a life of dependencies - on social welfare and goodwill of third sector organisations and volunteers. As asserted by several participants, higher education has the potential of giving them the feeling that they are the navigators of their own lives, encouraging thriving, beyond mere survival as currently supported by the state. In response to the 'crisis' - given the invisibility in national policy - an increasing number of universities have taken on the challenge to widen access to RBS, particularly through the introduction of scholarship programmes. Such initiatives are welcomed by third sector organisations, and the RBS, who seem to have the same high level of aspirations as the participants in Stevenson's and Willott's first study of this kind in England, from 2007. However, current institutional responses seem insufficient, and RBS remain virtually absent from universities. This, as discussed by participants, maybe because universities seem to have only a very superficial grasp of the socio-economic realities and the influences of the legal process of recognition of refugee status on the equality of opportunity in education. This is concerning, given the potential social and economic advantages afforded by HE participation (in particular for the otherwise disadvantaged individuals), of which universities are aware.

This study highlights not only the huge array of contemporary barriers to HE access encountered by RBS but - more importantly - explicitly identifies the many connections between the discrete factors, within and across the different identified categories (summarised in Fig. 6) - a novel and important finding.

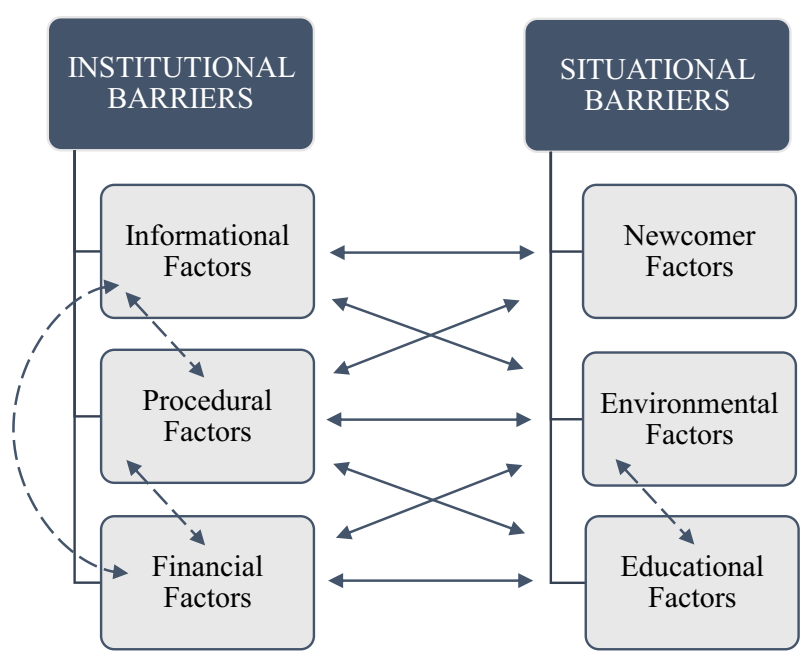

Fig. 6 Ways in which the institutional and situational barriers intersect 
The concept of super-disadvantage helps develop our understanding as it emphasizes the complexity and magnitude of disadvantage faced by RBS - which cannot be overcome without deliberate changes to outreach and support. Although some of the barriers are shared with other under-represented groups (as correctly recognised by the universities), many can be isolated as unique to RBS circumstances. Further, other 'common' barriers can consist of additional, distinctive layers of difficulty not affecting other disadvantaged groups — or be especially pronounced because of the contextual aspects of living in England as an asylum seeker or refugee. Although it is not claimed that the participants in this study represent a statistically valid sample of the refugee population in England (though due to the very nature of the forced migration phenomenon), it is difficult to speak of 'typical' cases, and it is questionable whether a sample can truly be 'representative' (Temple and Moran (2006) as cited in Stevenson and Willott (2007)), detailed demographic information was collected as part of the interviews, and no significant differences were found between genders, different age groups, nationalities or groups coming from different socio-economic background (prior to migration). Rather, all of the participants reported experiencing barriers to HE access - all of them facing multiple inhibiting factors simultaneously, all of them super-disadvantaged.

The findings here support previous research from the UK and elsewhere, which suggest that universities must engage the RBS themselves and third sector experts in planning and implementing outreach and support programmes for RBS to help universities understand the multiple enabling and inhibiting factors which affect them (see for example Bowerman et al. 2019). Whilst there are many great examples of universities already engaging in outreach work focused on RBS, both the formal evaluation of these (including through academic studies) and wider adaptation amongst universities are necessary, to challenge the socially unjust patterns in university participation of RBS. Universities can use the findings in this study, which identifies several areas for improvement, to evaluate and modify their admissions policies and procedures relating to RBS (including the dedicated scholarship programmes), and draw up strategies for enhanced outreach to refugee communities, to ensure that substantive equality of access is afforded to this currently perhaps most under-represented group in universities both in England - and in the world.

Acknowledgements I would like to acknowledge the contribution of the many sanctuary seekers in England, who have shared their experiences and life stories with me - their commitment to higher education learning continues to inspire me every day. I would also like to thank Prof. Paul Wakeling, Prof. Charlotte O'Brien and Dr. Sally Hancock for their insightful comments and ongoing support. Finally, I would like to thank two anonymous reviewers whose comments have greatly improved this manuscript.

Funding information Research work and data collection were supported by the Economic and Social Research Council doctoral studentship grant (Award reference 1652839), which is gratefully acknowledged.

\section{Compliance with ethical standards}

Conflict of interest The author declares that there are no conflicts of interest.

Informed consent Informed consent was obtained from all participants included in the study. Names of participants have been changed and no identifying information has been included in this article.

Open Access This article is licensed under a Creative Commons Attribution 4.0 International License, which permits use, sharing, adaptation, distribution and reproduction in any medium or format, as long as you give 
appropriate credit to the original author(s) and the source, provide a link to the Creative Commons licence, and indicate if changes were made. The images or other third party material in this article are included in the article's Creative Commons licence, unless indicated otherwise in a credit line to the material. If material is not included in the article's Creative Commons licence and your intended use is not permitted by statutory regulation or exceeds the permitted use, you will need to obtain permission directly from the copyright holder. To view a copy of this licence, visit http://creativecommons.org/licenses/by/4.0/.

\section{References}

Alberts, N., \& Atherton, G. (2017). Falling through the cracks: Enabling access to HE for unaccompanied asylum seeker children. London.

Allocation of accommodation policy. Verion 5.0, Home Office $\S$ (2017). Retrieved from https://assets.publishing. service.gov.uk/government/uploads/system/uploads/attachment_data/file/597382/Allocation-OfAccommodation-v5_0.pdf.

Antonucci, L. (2016). Student lives in crisis: Deepening inequality in times of austerity. Bristol: Policy Press Retrieved from https://books.google.co.uk/books?hl=en\&lr=\&id=EQVpDwAAQBAJ\&oi=fnd\&pg=PR1 $\& \mathrm{dq}=$ are+maintenance+loans+enough+for+students\&ots=qqGILZyOA1\&sig=E2PemneDILIuOoo4s2 elsvSVWvI\#v=onepage $\& \mathrm{q}=$ maintenanceloans $\& \mathrm{f}=$ false.

Bailey, L., \& Williams, S. J. (2018). The ethical challenges of researching refugee education. Qualitative Research Journal, 18(4), 359-370. https://doi.org/10.1108/QRJ-D-17-00010.

Bowerman, E., Crowley, E., Esenowo, I., Lambrechts, A., Lounasmaa, A., Murray, R., ... Squire, C. (2019). Improving access to Higher Education by forced migrants in the UK: recommendations for the sector. London. Retrieved from https://olivecourseuel.files.wordpress.com/2019/05/improving-accessto-highereducation-by-force-migrants-in-the-uk-1.pdf. Accessed 10 Feb 2020.

Clarke, V., \& Braun, V. (2013). Successful qualitative research: A practical guide for beginners. https://doi. org/10.1002/jmr.2361.

Cross, K. P. (1981). Adults as learners. San Francisco: Jossey-Bass.

Dench, S., \& Regan, J. (2000). Learning in later life: Motivation and impact. Retrieved from https://www. employment-studies.co.uk/resource/learning-later-life-motivation-and-impact.

Department for Business Innovation \& Skills. (2014). National strategy for access and student success in higher education. London. Retrieved from https://assets.publishing.service.gov. uk/government/uploads/system/uploads/attachment_data/file/299689/bis-14-516-national-strategy-foraccess-and-student-success.pdf.

Doyle, L., \& O’Toole, G. (2013). A lot to learn: Refugees, asylum seekers and post-16 learning. Retrieved from https://www.nuffieldfoundation.org/sites/default/files/files/RC-Alottolearn-web(1).pdf. Accessed 10 Feb 2020.

Elwyn, H., Gladwell, C., \& Lyall, S. (2012). "I just want to study": Access to higher education for young refugees and asylum seekers. Retrieved from https:/www.refugeesupportnetwork.org/resources/13-i-justwant-to-study-access-to-higher-education-for-young-refugees-and-asylum-seekers. Accessed 10 Feb 2020.

Eurydice. (2019). Integrating asylum seekers and refugees into higher education in Europe. National policies and measures. Brussels. https://doi.org/10.2797/548910.

Gorard, S., Adnett, N., May, H., Slack, K., Smith, E., \& Thomas, L. (2007). Overcoming barriers to HE. Stokeon-Trent: Trentham Books.

Hartley, L., Fleay, C., Baker, S., Burke, R., \& Field, R. (2018). People seeking asylum in Australia: Access and support in higher education Retrieved from https://www.ncsehe.edu.au/wp-content/uploads/2018/11 /Hartley_PeopleSeekingAsylum.pdf.

Home Office. (2016). Immigration Rules Appendix K: shortage occupation list. Retrieved from https://www.gov. $\mathrm{uk} /$ guidance/immigration-rules/immigration-rules-appendix-k-shortage-occupation-list.

Lambrechts, A. A. (2020a). Extending the welcome: The role of university-community partnerships in supporting refugees in England. In E. Sengupta \& P. Blessinger (Eds.), Civil society and social responsibility in higher education: International perspectives on university-community partnership. Bingley: Emerald Publishing In press.

Lambrechts, A. A. (2020b). The neglected minority: Refugee background students in England and Poland. (Unpublished doctoral dissertation). University of York, York, United Kingdom.

Lenette, C. (2016). University students from refugee backgrounds: Why should we care? Higher Education Research and Development, 35(6), 1311-1315. https://doi.org/10.1080/07294360.2016.1190524.

LIBERTY. (2019). The border controls dividing our communities-and how we can bring them down. A Guide to the Hostile Environment. Retrieved from https://www.libertyhumanrights.org.uk/sites/default/files/Hostile. Environment Guide - update May 2019_0.pdf. 
Meyer, J. W., \& Schofer, E. (2005). The worldwide expansion of higher education in the twentieth century. American Sociological Review. https://doi.org/10.1177/000312240507000602.

Morrice, L. (2009). Journeys into higher education: The case of refugees in the UK. Teaching in Higher Education, 14(6), 661-672.

Morrice, L., \& Sandri, E. (2018). Improving education for refugee background students: Research findings. Retrieved from https://www.sussex.ac.uk/education/cie/projects/completed. Accessed 10 Feb 2020.

Murray, R. (2019). Mapping opportunities available for forced migrant students at UK universities: Sanctuary Scholarships. Retrieved from https:/universities.cityofsanctuary.org/wp-content/uploads/sites/68/2019/10 /Mapping-Opportunities-v.2_Sept_2019.pdf.

OHCHR. (2018). Statement on visit to the United Kingdom, by Professor Philip Alston, United Nations Special Rapporteur on extreme poverty and human rights. Retrieved April 10, 2019, from https:/www.ohchr. org/en/NewsEvents/Pages/DisplayNews.aspx?NewsID=23881\&LangID=E.

Potter, J., \& Alderman, T. E. (1992). A profile of adult learners at the University of New Brunswick. Fredericton: University of New Brunswick, Department of Extension and Summer Session..

RISE. (2013). Research needs analysis - comparative report (Ireland, United Kingdom and Germany). Retrieved from https://riseproject.eu/ie/documents/2013/12/needs-analysis-report.pdf/. Accessed 10 Feb 2020.

Sanderson, A. (2001). Disabled students in transition: A tale of two sectors' failure to communicate. Journal of Further and Higher Education. https://doi.org/10.1080/03098770120050882.

Schneider, L. (2018). Access and aspirations: Syrian refugees' experiences of entering higher education in Germany. Research in Comparative and International Education, 13(3), 457-478. https://doi.org/10.1177 $/ 1745499918784764$.

Shakya, Y. B., Guruge, S., Hynie, M., Akbari, A., Malik, M., Htoo, S., ... Alley, S. (2010). Aspirations for higher education among newcomer refugee youth in Toronto: Expectations, challenges, and strategies. Refuge, 27(2), 65-78.

Stevenson, J., \& Baker, S. (2018). Refugees in Higher Education. In Debate, Discourse and Practice (First). Bingley: Emerald Publishing Limited.

Stevenson, J., \& Willott, J. (2007). The aspiration and access to higher education by teenage refugees in the UK. Compare: A Journal of Comparative and International Education, 37(5), 671-687.

UNHCR. (2019). Stepping up: Refugee education in crisis. Retrieved from https://www.unhcr. org/steppingup/wp-content/uploads/sites/76/2019/09/Education-Report-2019-Final-web-6.pdf.

United Nations. (2016). Resolution adopted by the General Assembly on 19 September 2016 A/RES/71/1.

Universities UK. (2017). Higher Education in numbers. Retrieved November 16, 2017, from http://www. universitiesuk.ac.uk/facts-and-stats/Pages/higher-education-data.aspx.

Publisher's note Springer Nature remains neutral with regard to jurisdictional claims in published maps and institutional affiliations. 